\title{
Erratum: Physics of giant electromagnetic pulse generation in short-pulse laser experiments [Phys. Rev. E 91, 043106 (2015)]
}

A. Poyé, S. Hulin, M. Bailly-Grandvaux, J.-L. Dubois, J. Ribolzi, D. Raffestin, M. Bardon, F. Lubrano-Lavaderci, E. D’Humières, J. J. Santos, Ph. Nicolaï, and V. Tikhonchuk

(Received 8 December 2017; published 16 January 2018)

DOI: 10.1103/PhysRevE.97.019903

This paper contains an error in Fig. 4. The magnetic field amplitude $B$ for the data should have been divided by a factor of $2 \pi$. Figure 1 presents the data after applying the $2 \pi$ correction and an improved suppression of the integration noise. A more accurate description of the amplitude emission will be provided in a future publication.

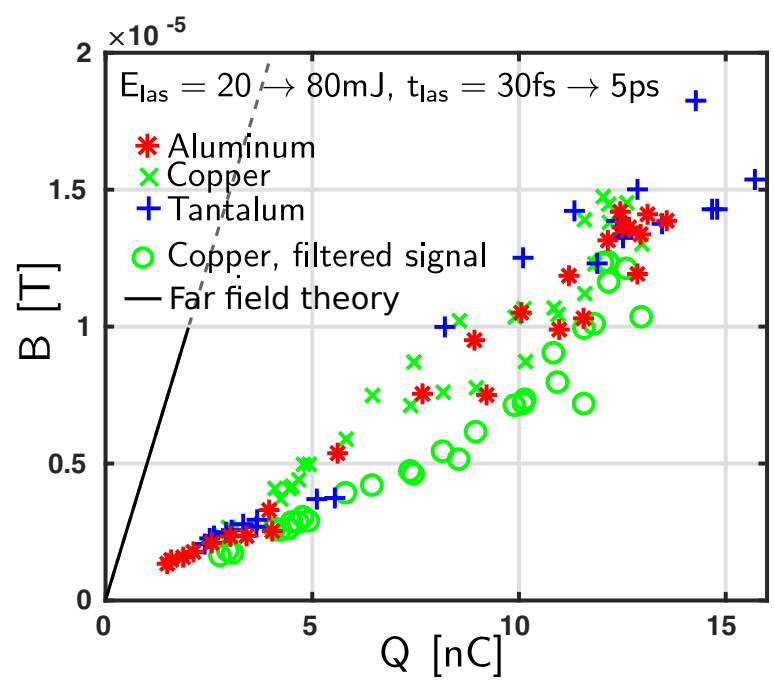

FIG. 1. The maximum emitted magnetic field versus the measured target charge for several laser parameters and different target materials (copper, aluminum, and tantalum). 